\title{
Knowledge transfer regarding the issue of animal health
}

\author{
${ }^{1}$ Department of Animal Nutrition and Animal Health, Faculty of Organic Agricultural Science, \\ University of Kassel, Nordbahnhofstraße 1a, 37213 Witzenhausen, Germany \\ ${ }^{2}$ Schulz von Thun Institute for Communication, Rothenbaumchaussee 20, 20148 Hamburg, Germany \\ Corresponding author:
}

Susanne Hoischen-Taubner, hoischen@ uni-kassel.de, Tel. +49 5542 98-1652, Fax: +49 5542 98-1581

\begin{abstract}
The transfer of knowledge and information gained from scientific investigations into farm practice is a primary constituent of applied agricultural science. The importance of this for both agricultural practice and agricultural science is in stark contrast with the fact that only very few studies have been conducted so far which have focussed on the framework required to achieve a successful transfer of knowledge.

Both the necessary prerequisites for and potential barriers to the successful transfer of knowledge regarding the issue of animal health have been the topic of this study taking different stakeholder perspectives into account. Based on a socio-cognitive approach to knowledge transfer, different communication techniques (e.g. estimations of animal health situations, environmental stakeholder analysis and dialogue cafes) were used to depict and record the views on and understanding of different stakeholders on the issue of animal health.

The analysis revealed divergence in the understanding of animal health, unclear responsibilities and self-referential judgements as barriers in the process of knowledge transfer. In the face of these constraints it is concluded that a targeted transfer of knowledge with respect to the issue of animal health is considerably compromised, requiring the creation of a framework which would provide the conditions for knowledge transfer. A common strategic goal, limiting the prevalence of production diseases, would help to bypass the current lack of a universally accepted definition of animal health. At the same time, this would function as a quality reference value in line with growing interest in animal welfare in livestock production.
\end{abstract}

Key words:

conflicting areas, stakeholder analysis, system justification, organic livestock farming, reflection

\section{Acknowledgements}

The authors gratefully acknowledge the Federal Ministry of Food and Agriculture (BMEL) for financial support based on a decision of the Parliament of the Federal Republic of Germany via the Federal Office for Agriculture and Food (BLE) under the Federal Organic Farming Scheme (BÖLN), grant no. 12OE016. The authors want to thank the participants for attending the workshops and their preparedness to contribute to the reflection. 


\section{Introduction}

In livestock farming animal health is a central issue of farm management due to its impact on performance and economic results (McInerney et al. 1992; Dijkhuizen et al. 1995). Improvements in animal health, which usually require additional financial or personnel resources, are judged against possible losses or improved performance. But, beside the impact of clinical and subclinical diseases on the economic outcome of a farm business, animal health becomes an issue for reasons beyond the individual farm business: the risk of foodborne diseases; the high quantities of antibiotics used in livestock production; the increasing risk of antimicrobial resistance; and the growing concerns of the general public regarding animal welfare (Rossi and Garner 2014).

The issue of animal welfare features highly in the discussion of livestock production. From the consumers' perspective, animal health, i.e. freedom from disease, is a precondition and integral element of animal welfare (Vanhonacker et al. 2010; Ventura et al. 2014). Ethical concerns regarding animal welfare are important drivers in themselves, and function as indicators for health and food safety (Harper and Makatouni 2002; Hermansen 2003; Magnusson et al. 2003). In organic agriculture the issue of animal health is strongly related to the organic principles of ecology, fairness, care, and health (Vaarst and Alrøe 2012; Sundrum 2014; International Federation of Organic Agriculture Movements (IFOAM) 2014) and is one of the most important choice criteria for consumers when buying organic products of animal origin (Zander and Hamm 2010).

Contrary to consumer expectation, organic farms in general do not provide higher animal health status than conventional ones (Sundrum et al. 2010; Cicconi-Hogan et al. 2013). In several studies the level of production diseases has varied more between individual farms than actual production methods (Vaarst et al. 2008).

Production diseases are multi-factorial and emerge from manifold risk factors and processes which in themselves would not necessarily cause clinical signs of a disease. Their occurrence indicates an overstrained capacity of the farm animals to cope with the living conditions provided by a specific farm situation (Gröhn et al. 1998; Nir 2003). Thus, animal health is a complex phenomenon emerging from the interaction of farm animals with the corresponding living conditions, and which cannot be deduced from single factors (Sundrum 2012).

In the context of knowledge transfer the complexity is further increased by the social system including farm management. It plays a key role in the improvement of the state of animal health because it directly affects the living conditions in which production diseases emerge.

Despite the efforts of the professional groups involved such as animal scientists, veterinarians, advisors and farmers, the prevalence of production diseases remains high (Sundrum 2014). Moreover, even in organic agriculture, where animal health is of significant value for consumer confidence; where regulations provide improved living conditions for animals; and where farmers can rely on a broad range of advisory services, the level of production diseases in general is not better compared to conventional systems. This situation questions the effectiveness of the previous approach to knowledge transfer with respect to animal health. The aim of the current study was the identification of prerequisites for successful knowledge transfer as well as the detection of barriers and constraints to this process.

\section{Knowledge transfer and the concept of knowledge}

Knowledge transfer usually describes processes of exchange, often from an expert site to a novice site, leading to new knowledge and its application (Carlile and Rebentisch 2003; Ringberg and Reihlen 2008; Wilkesmann and Wilkesmann 2011). Roux et al. (2006) describe several domains involved in the transfer of knowledge as science, policy and management as well as society, arriving at different 
degrees of codification and practical application. With respect to the issue of animal health, several stakeholder groups are involved such as farmers, veterinarians, advisors, and scientists but also consumers, the general public and retailers. Regarding the issue of animal health, scientific study is usually accepted as the expert site, the creator of explicit knowledge, based on research in the field of animal health. The subsequent transfer of knowledge is directed at farm management, aiming for change and the implementation of strategies and measures. Dissemination and generation of information and knowledge regarding animal health is a process of communication largely influenced by individual circumstances and mind-sets (Leeuwis and Ban 2004; Lam et al. 2011; Jansen and Lam 2012).

Figure 1 illustrates the underlying concept of knowledge in this study. It refers to the widely-used hierarchy of data, information and knowledge (Zins 2007), where data are seen as the raw material, based on observation, describing disconnected facts. Information is based on data, which are organised and structured for a specific purpose and according to the context of use. Based on data and information, knowledge is constructed by the individual through personal interpretation and understanding. Accordingly, the transformation from data to information and information to knowledge is largely dictated by the context of data assessment, aggregation and interpretation as well as personal interpretation, individual parameters and mind-sets (Arce and Long 1987; Probst et al. 2006; Liyanage et al. 2009). In their socio-cognitive approach to knowledge transfer, Ringberg and Reihlen (2008) emphasise the importance of cultural and private models, the level of categorical or reflective thinking and the level of social interaction for the cognitive process leading to different types of knowledge transfer outcomes. Harris (1994) referred to the individual knowledge structure enabling efficient processing of incoming information as "schema". They represent a cognitive structure guiding the processing of incoming information and are based on experiences and existing knowledge. When identifying problems, some authors attribute greater importance to individual patterns of perception than to the severity of the problem itself (Beratan 2007; Nerdinger 2012; Richert et al. 2013).

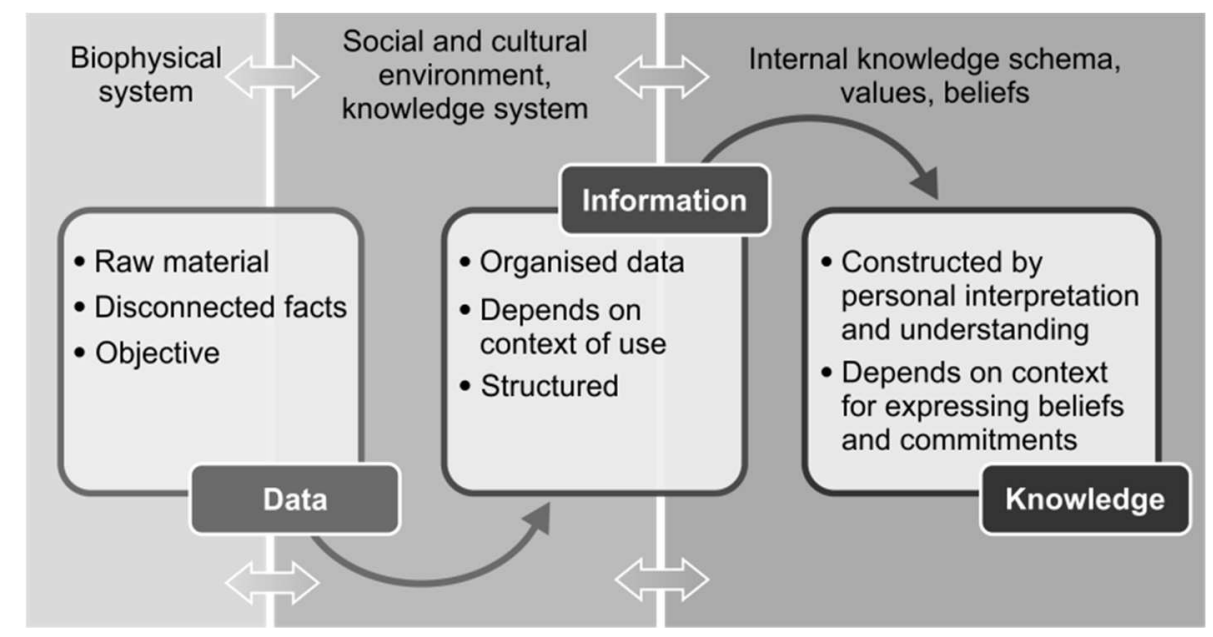

Fig 1 Underlying concept of knowledge, based on Arce and Long 1987; Harris 1994; Probst et al. 2006; Zins 2007; Tàbara and Chabay 2013

The existence of data in biophysical systems, the observation of data by humans, aggregation to information and transformation to subjective knowledge happens within a context. Several authors describe the social and cultural environment as knowledge system, indicating the complex, open and interacting character in which the scope and aim of data assessment is defined and data is structured to information (Arce and Long 1987; EU SCAR 2012; Tàbara and Chabay 2013). From an individual's view the environment forms the live-world, in which knowledge is gathered and assessed for its usefulness (Arce and Long 1987). Within the knowledge system live-worlds are as manifold as the individuals involved. 
Tàbara and Chabay (2013) describe and criticise the prevailing distinction made in science between the social knowledge system and the biophysical system in the field of environmental and sustainability research. They describe the biophysical system as the natural system, providing information that emerges from inherent processes. The same applies in the context of animal health, where the living systems of animals with their inherent capacities to adapt to varying living conditions, meets the social and cultural environment of livestock farming.

As indicated in Figure1, the spheres of biophysical systems, human knowledge systems and internal knowledge are interlinked and influence each other. Within this framework of knowledge it becomes clear that knowledge is seen as an open system with several actors and perspectives. Based on this understanding the study aimed to assess different perspectives on the topic of animal health, trying to reveal prerequisites and constraints for a successful transfer of knowledge, resulting in improved animal health.

\section{Material and methods}

According to the framework outlined above, the study aimed to identify the live-worlds of stakeholders involved in the process of knowledge transfer with respect to animal health. The process required not only the recording and observation of assessments but also a specific level of reflective thinking by the participants. Therefore, core elements of the study were interdisciplinary collaboration with an expert on communication and the use of several communication techniques in stakeholder workshops.

\section{Participants}

In a first stage of the research project farmers (8), agricultural and veterinarian advisors (9), as well as animal scientists (9), were identified as primary stakeholders in the process of knowledge transfer on the issue of animal health. They are directly involved and affected. A flow of information regarding animal health aimed at a reduction of production diseases cannot happen without them (Freeman 1984; Clarkson 1995).

In a second stage 13 representatives of Non-Governmental Organizations (NGO) in the field of farmers' organisations, consumer and animal protection as well as food retailers were involved. They belong to the broader range of secondary stakeholders, who are not directly linked to the transfer of information but represent a system of values from which they influence the socio-economic context (Clarkson 1995). They affect to a large degree ethical values, economic and ultimately the legislative environment framing the topic of animal health.

Participants were expected to represent a range of possible perspectives on animal health in the different workshop groups, rather than a representative average opinion. Therefore, a non-probability sampling method was used to select the participants. The people initially invited were selected from the target groups of farmers, advisors and researchers as well as actors from relevant stakeholder groups identified in the first stage of the project. They were further asked to name other interested persons to be invited.

\section{Workshops}

Based on the underlying concept of knowledge and the importance of individual perspectives, a series of workshops was planned to determine different perspectives on the issue of animal health and reflect on barriers in the transfer of knowledge. Based on findings from this stage secondary stakeholders were invited to participate in the project. The sequence of workshops is illustrated in figure 2 . 

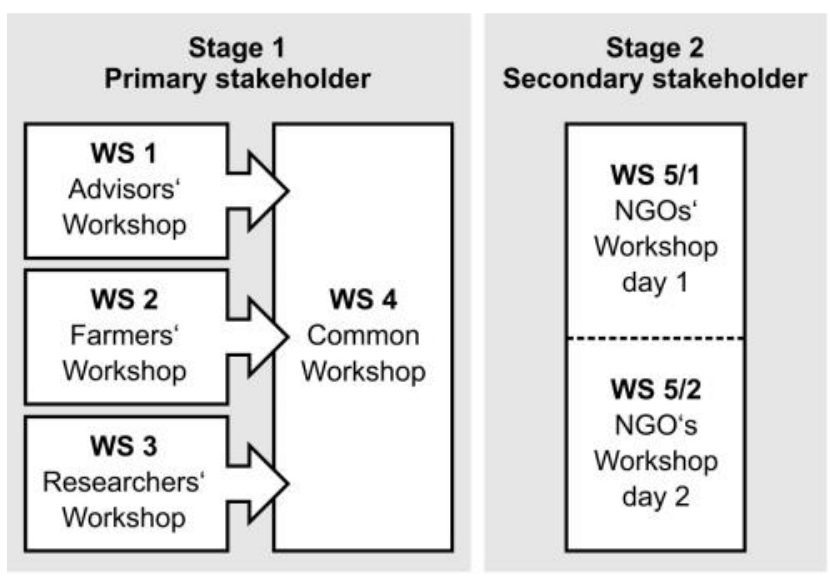

May $2013>$ June $2013>$ February 2014

Fig 2 Sequence of workshops

The outline of the workshops as well as the assessment of the process addressed the importance and complexity of communication and were supported by an expert on communication and moderation. Tools from communication science were employed. In order to foster unbiased debates in the workshops, the project team limited itself to an observer role, leaving the moderation of the workshops to the skilled and impartial moderator.

In stage one, separate workshops for each stakeholder group (WS1, WS2 and WS3) were held to assess their specific perspectives. The section was complemented by a common workshop (WS4) with all participants. Due to the heterogeneity of secondary stakeholders, no separate workshops for subgroups were held in the second stage, but a two-day workshop (WS5/1 and WS5/2) was held to allow for reflection on perspectives and scenarios according to the first stage.

The course of the workshops was designed to determine the individual perception of the issue addressed, to picture the context framing the transfer of knowledge on animal health, to reflect on barriers and to think about future scenarios. Several communication techniques were selected according to the aim and adapted to the workshop groups (table 1). To assess the individual perception of animal health, the workshops started with a (i) brief estimation of different animal health situations including (ii) the ranking of measures in WS1 - WS3. The context forming the framework conditions for communication and decision-making was addressed by (iii) individual environmental stakeholder analysis (ESA).

In the common workshop at the first stage (WS 4), interim results from WS 1, 2 and 3, as well as a brief reflection from the communication expert were reported and discussed (iv). Thereafter, the participants worked in small groups on topics identified during the separate workshops and considered their options for action (v).

The second day of WS 5 (secondary stakeholder) was aimed at a change in perspectives (vi), analogues to WS4 for the primary stakeholders, and elaborating options to act upon (vii).

Due to time restrictions, two participants were not able to attend WS5. In a separate consultation (WS6, table 1) they worked on ESAs in a similar way to the other workshop participants and these were included in this paper. 
Table 1: Communication techniques applied to the workshop groups

\begin{tabular}{|c|c|c|c|c|c|c|c|c|}
\hline & Workshop (WS) & 1 & 2 & 3 & 4 & $5 / 1$ & $5 / 2$ & 6 \\
\hline & $\mathrm{n}=$ & 9 & 8 & 9 & 26 & 11 & 10 & 2 \\
\hline \multirow[t]{3}{*}{$\mathrm{i}$} & Estimation of animal health situations on a Visual & nal & gue & ale & VAs & & & \\
\hline & - by pictures and video sequence & & & & & & & \\
\hline & - by data sheets & & & & & & & \\
\hline ii & Ranking of measures & & & & & & & \\
\hline iii & Environmental Stakeholder Analysis (ESA) & & & & & & & \\
\hline iv & Reflection on fault lines & & & & & & & \\
\hline $\mathrm{V}$ & Dialogue cafes on barriers and areas for action & & & & & & & \\
\hline vi & Walking in the shoes of... & & & & & & & \\
\hline vii & Future Scenarios & & & & & & & \\
\hline
\end{tabular}

The outcome of the workshops was evaluated by qualitative content analysis, descriptive statistics, and inter-rater reliability, focussing on the communication structure including role models.

\section{Estimation of animal health situations}

For each group workshops started with a brief estimation of different animal health situations. A questionnaire was designed to determine perceptions, interpretations and considerations with respect to further actions to improve the animals' situation. Five different animal health situations were presented to the participants by pictures (2), video (1), and data sheets (2). The first situation was a picture of an acute udder inflammation in a single dairy cow. Monthly milk recording data on somatic cell counts (SCC) in a dairy herd, indicating the number of animals in different categories of SCCs on the farm level made up the second situation. This was followed by a picture of a clinical udder infection of a sow together with young piglets. The fourth situation was described by another data sheet, showing anatomical-pathological findings on lesions of lungs in fattening pigs above average, recorded as routine meat inspections at the slaughterhouse. The last health problem was illustrated by a short video, showing an obvious lame dairy cow. The participants answered both open-ended and closed questions on the findings individually.

Corresponding with the agenda in the first stage of the project, the participants in the second stage (WS 5/1) were asked to rate the data on SCC and lung lesions which were supplemented by short explanations due to the greater distance of the participants from the topic.

\section{Assessment of single animal's general condition and the herd health status:}

For each of the findings presented, the participants were asked individually to either give their estimation of the animals' general condition (situations 1,3, and 5) or of the herd health status (situations 2 and 4) on a visual analogue scale (VAS). Visual analogue scales are an instrument used to measure subjective attitudes by indicating a position on a continuous line between two end-points. VAS are used to measure the perception of pain in humans but were also validated for the recording of subjective observer assessments of lameness and pain in animals (Hudson et al. 2004).

For the situation presented by the pictures and the video, the participants were asked to mark the impairment of the animals' general condition on a $10 \mathrm{~cm}$ horizontal line between the endpoints "no impairment" and "severe impairment". For the situations presented by data, the herd health status was assessed by marking a point on a line between the end-points "very good" (0) and "very bad" (10). 


\section{Ranking of measures to improve a situation:}

For each of the five situations a set of six to eight measures was ranked by the participants according to their estimation of importance. The ranking of measures was compared by Kendall's coefficient of concordance (Kendalls' W) within and between the workshop groups. Kendalls' W is used to evaluate the degree of association in a panel of observers ranking the same set of items (Legendre 2010). The range of Kendalls' W covers values from 0 to 1 in which high values derive from similar rankings.

\section{Environmental stakeholder analysis:}

Environmental stakeholder analysis (ESA) is an instrument adopted by the project management to help identify different stakeholders and influencing variables, in order to analyse their interests in the project and to better understand their relationship (Vetter 2012). At the same time it is a method used to draw up a cognitive map, reflecting the live-world of a person (Arce and Long 1987). In this study, the ESA was used to gain a visual overview of people, institutions, factors, and framework conditions in terms of animal health. Listing stakeholders and relevant factors was the first step in undertaking an ESA. In accordance with their significance for animal health, the issues were noted on cards of three different sizes (small, medium, large $=$ little, medium, great importance). The cards were placed on posters with distance and size dictating their relation to the topic and each other. Lines, arrows and symbols were used to express the quality of relations (figure 3). In the separate workshops all of the participants were asked to work on an individual environmental (stakeholder) analysis and to present their estimation to the workshop group.
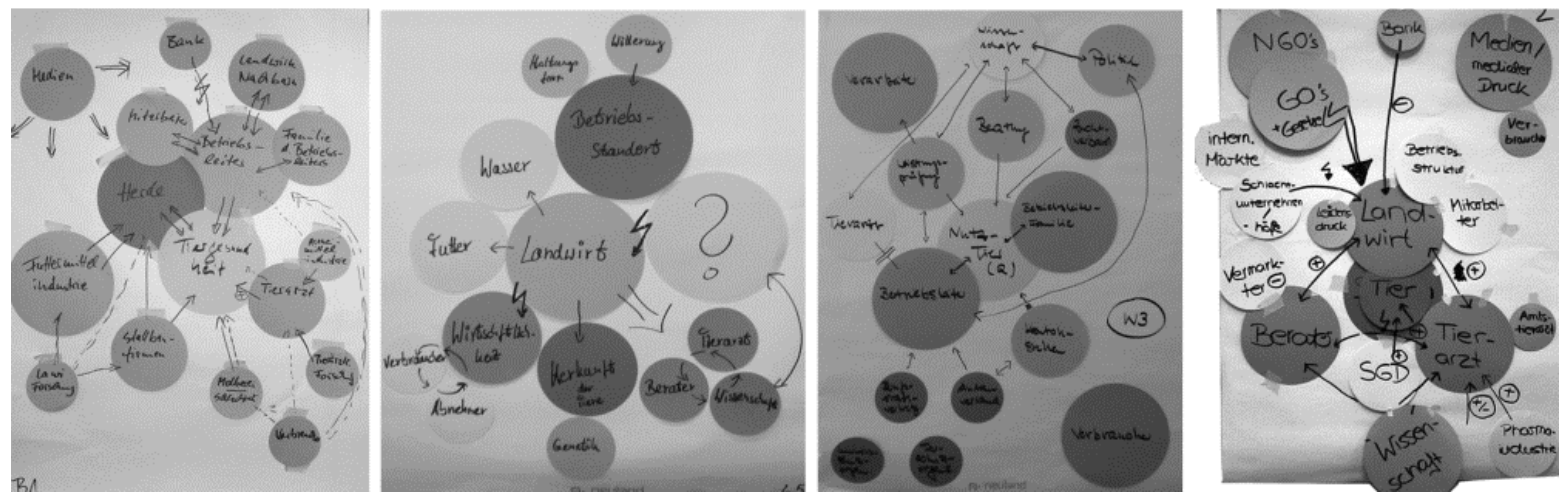

Fig 3 Examples of environmental stakeholder analysis from the workshops with advisors, farmers, researchers and secondary stakeholders

For further analysis, the issues were condensed into categories, following the steps of qualitative content analysis (Mayring 2010). The process included the feedback given by the workshop participants after a presentation during the common workshop (WS 4). The issues were evaluated according to their size and position using basic statistics. The card size was coded from 1 (small) to 3 (large); the position was valued on a scale from 1 to $6(1=$ peripheral, $6=$ central $)$.

\section{Reflection on fault lines and dialogue cafes on barriers and areas for action}

In the common workshop (WS4) of stage 1, interim results on the estimation of animal health situations and from the ESA were reported back to all participants, providing the option to give a communicative validation in the form of a discussion in small groups and a presentation of the main outcome, written on moderation cards, to the group and the project team. In addition, the communication expert presented a summary from the perspective of communication psychology, emphasising conflicting interests and fault lines revealed by the preceding workshops. Conflicting interests were identified and discussed using the concept of "square of values" described by Schulz von Thun (2010), supporting discussions in a respectful atmosphere and a change of perspectives, aiming for workable solutions. 
Thereafter, the participants worked in small groups on the topics identified during the first workshops and reflected on options for action. Group discussions took place as dialogue-cafés, an adaptation of the methodology of the world-café (Brown 2005). The process of dialogue cafés consisted of two rounds. In the first round the workgroups were mixed from all three stakeholder workshops to discuss selected barriers identified in the separate workshops. In the second round of dialogue cafés, the participants worked at three tables within their stakeholder group and at the fourth table in a mixed group on the question as how best to define specific areas of action. Results were presented to the whole group.

\section{Walking in the shoes of... and future scenarios}

On day two of the secondary stakeholder workshop (WS5/2), a role-playing game aimed at a change in perspectives. The participants were assigned to differing roles and answered questions concerning the topic of animal health from this perspective. Answers were collected on flip charts and presented to the whole group. The change of perspective was intended to foster the understanding of other perspectives in the field and support the elaboration of feasible future scenarios.

While discussing in small groups, the participants were asked to work on a future scenario and realistic action plan targeted at an increased animal health status in 2020. Again, the scenarios were presented to the whole group.

\section{Results}

\section{Assessment of herd health situations:}

Tables 2 and 3 represent the average estimations regarding the animals' general condition (findings 1, 3 and 5) and the herd health status (findings 2 and 4) on a visual analogue scale (VAS) for each workshop. The assessment regarding a lame cow, presented by a short video sequence, varied the least. The assessment on the VAS ranged from 7.0 in the farmers' workshop up to 10 in the workshops of farmers and researchers. Concerning the findings presented by pictures, the assessments varied more both within (finding 1) and between the workshop groups (finding 3). The estimations regarding the herd health status represented by data on SCC and findings at the slaughterhouse showed the highest variation for both situations in the workshop of advisors and least in the workshop of farmers.

Table 2: Average estimations from three workshop groups on the impairment of animals' general condition based on pictures and a video sequence

\begin{tabular}{|c|c|c|c|c|c|c|c|c|}
\hline & Findings & Workshop & $\mathbf{N}$ & Minimum & $\begin{array}{c}25^{\text {th }} \\
\text { percentile }\end{array}$ & $\begin{array}{c}5^{\text {th }} \\
\text { percentile } \\
\text { (median) }\end{array}$ & $\begin{array}{c}{75^{\text {th }}}^{\text {percentile }}\end{array}$ & Maximum \\
\hline \multirow{3}{*}{1} & \multirow{3}{*}{$\begin{array}{l}\text { Picture, } \\
\text { udder, } \\
\text { cow }\end{array}$} & Advisors & 9 & 1.9 & 6.2 & 6.6 & 8.0 & 9.4 \\
\hline & & Farmers & 8 & 2.6 & 6.3 & 6.8 & 7.9 & 8.5 \\
\hline & & Researchers & 9 & 2.3 & 5.1 & 7.1 & 8.2 & 9.5 \\
\hline \multirow{3}{*}{3} & \multirow{3}{*}{$\begin{array}{l}\text { Picture, } \\
\text { udder, } \\
\text { sow }\end{array}$} & Advisors & 9 & 5.8 & 7.6. & 8.2 & 8.8 & 10.0 \\
\hline & & Farmers & 8 & 5.5 & 7.6 & 8.1 & 8.2 & 8.4 \\
\hline & & Researchers & 9 & 1.8 & 5.0 & 6.5 & 7.7 & 9.5 \\
\hline \multirow{3}{*}{5} & \multirow{3}{*}{$\begin{array}{l}\text { Video, } \\
\text { lameness, } \\
\text { cow }\end{array}$} & Advisors & 9 & 7.3 & 7.7 & 8.5 & 9.3 & 9.5 \\
\hline & & Farmers & 8 & 7.0 & 8.5 & 9.5 & 9.7 & 10.0 \\
\hline & & Researchers & 9 & 7.5 & 8.6 & 9.3 & 9.5 & 10.0 \\
\hline
\end{tabular}

Visual Analogue Scale end-points: $0=$ no impairment, $10=$ severe impairment 
Table 3: Average estimations from three workshop groups on the herd health status based on data on somatic cell counts and lung lesions

\begin{tabular}{llcccccc}
\hline \multicolumn{1}{c}{ Findings } & Workshop & $\mathbf{N}$ & Minimum & $\begin{array}{c}\mathbf{2 5}^{\text {th }} \\
\text { percentile }\end{array}$ & $\begin{array}{c}\mathbf{5 0}^{\text {th }} \\
\text { percentile } \\
\text { (median) }\end{array}$ & $\begin{array}{c}\mathbf{7 5}^{\text {th }} \\
\text { percentile }\end{array}$ & Maximum \\
\hline \multirow{2}{*}{$\begin{array}{l}\text { Data, } \\
\text { SCC, } \\
\text { dairy herd }\end{array}$} & Advisors & 9 & 3.7 & 6.5 & 8.2 & 8.9 & 9.6 \\
& Farmers & 8 & 3.4 & 5.8 & 6.6 & 6.8 & 8.3 \\
& Researchers & 9 & 3.3 & 7.0 & 7.4 & 8.3 & 8.8 \\
\cline { 2 - 8 } & NGOs* & 11 & 2.3 & 4.0 & 6.3 & 6.9 & 7.8 \\
\hline \multirow{2}{*}{$\begin{array}{l}\text { Data, } \\
\text { lung lesions, } \\
\text { pigs }\end{array}$} & Advisors & 9 & 2.9 & 4.9 & 7.8 & 8.5 & 10.0 \\
& Farmers & 7 & 5.3 & 6.4 & 6.7 & 7.0 & 7.5 \\
\cline { 2 - 8 } & Researchers & 9 & 3.8 & 6.3 & 6.9 & 7.6 & 8.2 \\
\hline
\end{tabular}

Visual Analogue Scale end-points: $0=$ very good, $10=$ very bad; * missing values: $\mathrm{n}=2$

\section{Ranking of measures to improve a situation:}

The participants' level of agreement concerning the ranking of measures was assessed by Kendall's coefficient of concordance, which ranges from 0 (no agreement) to 1 (total agreement). The results presented in table 4 show varying agreement amongst participants for different situations ranging from 0,129 to 0,435 . In the advisors' and farmers' workshops, the agreement between participants in ranking the measures according to their importance was highest for the measures presented for the situation represented by the somatic cell count of a dairy herd and weakest for the finding presented by a picture of an inflamed udder of a cow. In the researchers workshop agreement between the participants was higher for the finding presented by a picture of an inflamed udder of a sow and only weak for the set of measures regarding the inflamed udder of a cow. Within workshop groups, the ranking of measures in some situations was indistinguishable from coincidental accordance indicated by $\mathrm{p}>0.05$.

Table 4: Agreement from three workshop groups on the importance of measures to be applied in different animal health situations

\begin{tabular}{|c|c|c|c|c|c|c|c|c|c|c|c|c|}
\hline \multirow{2}{*}{$\begin{array}{l}\text { Workshop } \\
\text { Finding }\end{array}$} & \multicolumn{3}{|r|}{ All } & \multicolumn{3}{|c|}{ Advisors } & \multicolumn{3}{|c|}{ Farmers } & \multicolumn{3}{|c|}{ Researchers } \\
\hline & $\mathrm{N}$ & $\mathrm{W}^{1}$ & $\mathrm{p}$ & $\mathrm{N}$ & $\mathrm{W}^{1}$ & $\mathrm{p}$ & $\mathrm{N}$ & $\mathrm{W}^{1}$ & $\mathrm{p}$ & $\mathrm{N}$ & $\mathrm{W}^{1}$ & $\mathrm{P}$ \\
\hline 1: Udder, cow & 26 & 0.129 & 0.01 & 9 & 0.221 & 0.08 & 8 & 0.248 & 0.78 & 9 & 0.118 & 0.38 \\
\hline 2: SCC, dairy herd & 24 & 0.435 & 0.00 & 8 & 0.566 & 0.00 & 7 & 0.517 & 0.00 & 9 & 0.372 & 0.01 \\
\hline 3: Udder, sow & 26 & 0.350 & 0.00 & 9 & 0.448 & 0.00 & 8 & 0.281 & 0.03 & 9 & 0.440 & 0.00 \\
\hline 4: Lung lesions, pigs & 25 & 0.265 & 0.00 & 9 & 0.299 & 0.02 & 7 & 0.331 & 0.04 & 9 & 0.232 & 0.06 \\
\hline 5: Lameness, cow & 26 & 0.300 & 0.00 & 9 & 0.376 & 0.01 & 8 & 0.269 & 0.06 & 9 & 0.437 & 0.00 \\
\hline
\end{tabular}

\section{Environmental stakeholder analysis:}

The 39 ESAs contained a total of 583 terms of which 460 were related to people, groups and institutions in the field of animal health. The terms were condensed into 28 categories, 17 of them 
representing stakeholder groups. In figure 4, these stakeholders are represented in a stacked column diagram, showing the number of items related to each category from the different workshops.

Terms not related to stakeholders were mentioned less frequently and focused on the farm situation (forage, barn, external factors), management aspects (control, economy, data, organisation) or addressed more general influences (breeding, further education).

Most items were related to the categories advisor, veterinarian and purchase \& trade. The categories animal, policy \& administration and farmer were mentioned considerably less frequently in the ESAs, followed by NGOs, supplier, consumer, and science.

The most important stakeholder in the field of animal health, reflected by the average size of cards (2.9) and a SD of 0.3, was the farmer. The next categories in the ranking relate to the direct environment of the farms such as, employees ( $2.2 \pm 0.7)$, family ( $2.1 \pm 0.8)$, and animal (2.1 \pm 0.9$)$. Important categories from outside this inner circle were purchase \& trade $(2.0 \pm 0.7)$, followed by veterinarian (2.0 \pm 0.7$)$, policy \& administration (1.9 \pm 0.8$)$, advisor, and colleagues (all $1.9 \pm 0.7)$. The category science appeared in $26 \mathrm{ESAs}$, while its importance was valued on a comparably low level (1.5 \pm 0.7$)$, the same as for the category NGOs.

The category veterinarian was seen in 35 ESAs while advisor and farmer appeared in 30 and 32 ESAs, respectively. While farmer was placed centrally in most of the posters (average position 5.2 \pm 0.8 ), veterinarian (average position 3.6 \pm 1.1 ) and advisor (average position $3.3 \pm 1.1$ ) occurred at some distance to the centre.

While the posters from the farmers' workshop included fewer terms and were focussed on the farm situation, those from the advisors' and the researchers' workshop illustrated a broader environment including further actors and the farms' business environment whereas factors at farm level were missing. ESAs from secondary stakeholders revealed a broader spectrum of stakeholders, including $N G O s$, purchase \& trade as well as policy \& administration to a larger degree.

For some categories the frequency and size varied considerably between the workshops. The categories barn and forage were found in nearly all ESAs in the farmers' workshop and in only one ESA from the other workshops. Terms in the category purchaser \& trade, family and economy were seen in nearly all ESAs in the advisors' workshop while they appeared less often in other workshops. The categories animal and science were found in nearly all ESAs in the researchers' workshop and the category NGOs was mostly used in the ESAs of secondary stakeholders. 


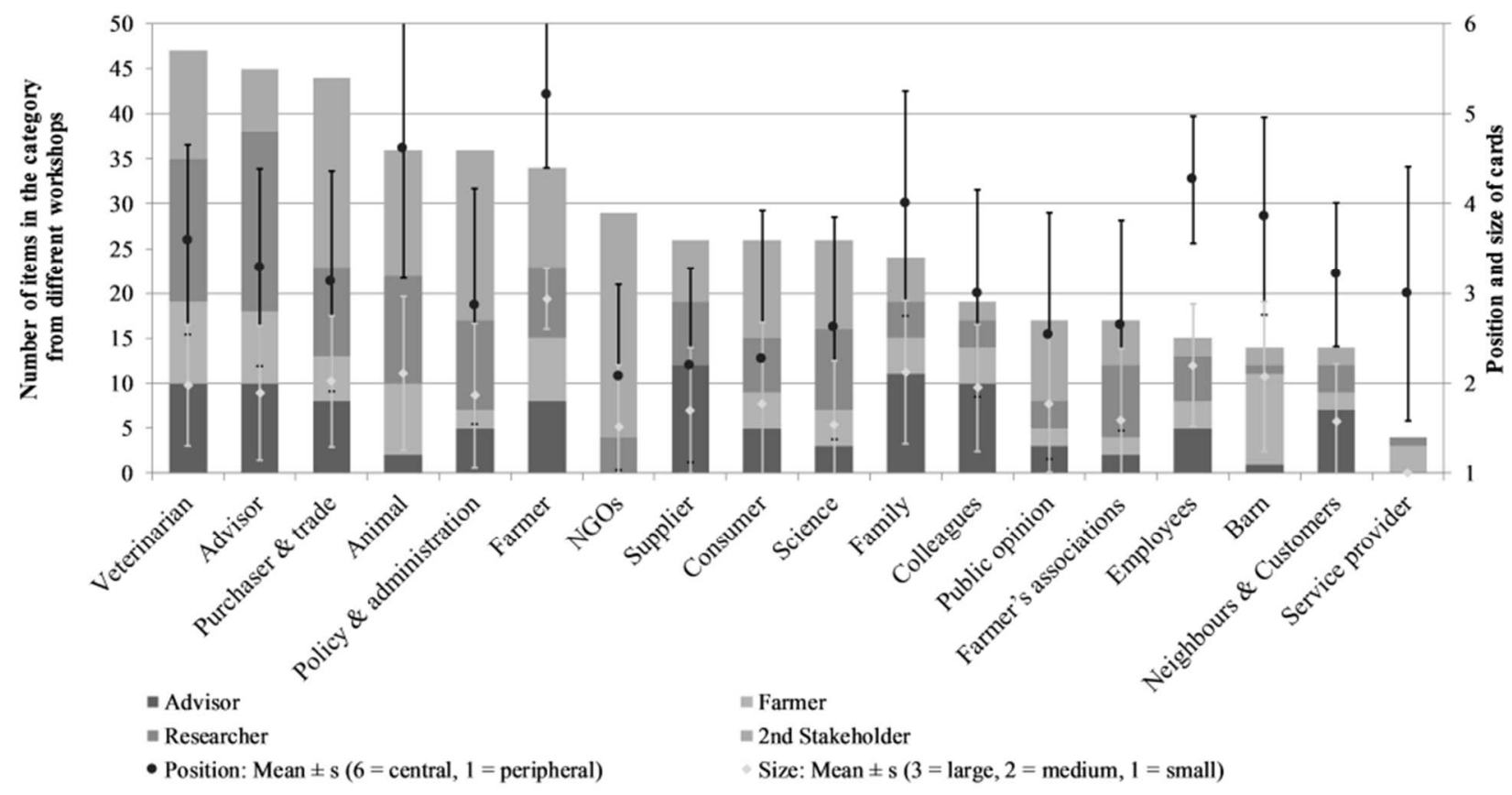

Fig 4: Frequency, average position and size of stakeholders identified in 39 Environmental Stakeholder Analysis

\section{Reflection on fault lines and dialogue cafes on barriers and areas for action}

All workshop groups identified animal health as a significant value, desirable for all participants. Nonetheless, during the workshop process three main areas of conflict emerged from group discussions (table 5) and were subsequently presented to the participants in the common workshop.

Table 5: Fault lines in connection with animal health

$$
\begin{array}{rll}
\text { Animal health } & \Leftrightarrow & \text { Economy } \\
\text { Detailed knowledge } & \Leftrightarrow & \text { Holistic view } \\
\text { Individual autonomy } & \Leftrightarrow & \text { Public interest }
\end{array}
$$

The conflicting areas of animal health and economy at farm level were especially an issue for the group of farmers. The dichotomy between the application of detailed knowledge and the requirement for a holistic view challenges agricultural science: the complexity of individual farm conditions impedes the applicability of findings which are based on detailed, objective knowledge, gained by research in specific circumstances. The farmers' claim to autonomy in the form of independent decisions in their businesses conflicts with public interest in the animal health issue as a common good. Pushing for the resolution of conflicts and weighing out opposing viewpoints was expected to lead to intense discussions between stakeholders. However, the participants seemed to avoid discussing controversial issues and persisted with their previous line of argument without being able to see things from another point of view.

From a list of topics revealed during the separate workshops, the participants chose (i) animal health, (ii) transfer of knowledge, (iii) reflection on barriers, and (iv) understanding of roles to work with in the first round of the dialogue cafés.

The discussion on the topic of animal health revealed quite different understandings of the concept among the participants. Furthermore, participants identified varying approaches, referring to different levels like the single animal or herd prevalence and different aims. In line with this was the identification of inadequacy in the definition of animal health and benchmarking as a barrier to the 
process of knowledge transfer. The handling of experiential knowledge and a lack of communication were further topics. Conflicts in the understanding of roles were named as (i) farmers, feeling patronised and not appreciated; (ii) advisors, trapped between the expectation to solve a problem and the dependency on farmers decision to implement; (iii) scientists, asking for clarification of tasks and referring to the problem of third-party funding.

Based on these insights, the second round of dialogue cafés yielded the following specific areas of action: (i) increasing motivation, (ii) standards and indicators, (iii) models for cooperation, (iv) creating options for communication, (v) holistic view, (vi) significance of animal health.

\section{Walking in the shoes of ... and future scenarios}

Three scenarios aimed at improved animal health status were worked on. One topic was the identification of indicators for animal health fixed either in legal requirements or voluntary values and norms. Other topics were regulations for treatments including the use of antibiotics, improved animal housing conditions and the policing of regulations. Participants identified veterinarians, advisors, farmers, scientists, surveillance authorities, and retailers as responsible actors.

Asked for own concrete first steps in the next four months, wait and see was mentioned in all three groups, combined with the plan to follow business as usual (actions currently on the agenda).

\section{Discussion}

While the presentation of results followed the order of the topics in the workshops, this discussion starts with a more general view on the framework conditions for communication on production diseases and proceeds to the individual perception of both, the context and the issue of animal health.

\section{Context of animal health}

The individual ESAs created by different stakeholders depict the system of communication and the operational structure for the transfer of knowledge on animal health. In most ESAs, veterinarians, advisors and farmers were identified as the main actors in the field of animal health. In total, 17 Stakeholder groups were identified, several of them consisting of distinguishable subgroups such as advisors acting for companies, farmers' organisations or official extension services. Stakeholders identified in the field of animal health largely represent actors along the value-creation chain, but also address a wider field of people, organisations and companies who can affect or are affected by animal health, thereby matching the early definition of the term 'stakeholder' by Freeman (1984). The categories Public opinion, Neighbours \& Customers, Family and Animal are examples from this broader frame. While the participants valued the possibility of collaboration in the project on an equal footing, it has to be acknowledged that the stakeholders in real life have quite different perspectives and spheres of action.

From the viewpoint of the farmers, advisors and animal scientists involved, the transfer of knowledge on animal health takes place in a network formed by the identified stakeholders. The structure matches the characterisation of a network by Schlippe and Schweitzer (2012) including fuzzy and flexible borders, informal membership, varying constellation of members and a lack of binding rules and agreements. Members in the network may interact and install contracts in their relationship but this is not mandatory. In such an environment the understanding of roles and responsibilities is largely based on self-perception. 
In the ESAs the perception of rights, duties, expectations, norms and behaviours assigned to the participants own role and those of the other actors was represented by the size and position of issues and their connections. The frequency in which each stakeholder group was mentioned in the ESAs varied, indicating that their role in relation to animal health is valued differently. This was underlined by the differing levels of importance allocated to the topic. The variation was low for the assigned importance of the farmer but quite high for most of the other stakeholders. The variation between the ESAs concerning these values indicates not only differing expectations but also a differing understanding of roles and responsibilities. Not feeling responsible would be a significant obstacle to the process of knowledge transfer, because it prevents the demand for specific knowledge to change a situation and relocates the need for action to other stakeholders.

This conclusion is supported by other authors, assessing the food chain and its actors: Most stakeholders named in the ESAs belong to the value-creation chain for products from animals' origin. It is characterised by specialisation both in conventional and organic farming. Specialisation within the supply chain resulted in fragmentation of tasks and management responsibilities. van Bueren et al. (2014) conclude in their analysis of the Dutch chicken meat chain that the fragmentation encourages individual actors to neglect their responsibility. They refer to the concept of 'organised irresponsibility' described by Beck (1992) showing the incapability of society in dealing with risk and responsibilitiy within a fragmented system. Kjærnes (2012) elaborates in this context on the final shift of responsibility to the consumer when she states: „The "problem" is located in the character of citizens instead of in specific social arrangements." Jonge and Trijp (2013) described the situation in the supply chain in European livestock production as inert regarding change and innovation in the field of animal health and welfare. They refer to the status quo as 'system lock-in', resulting from stakeholders' conflicting interests, the prioritisation of economic rules, and specific characteristics of the meat supply chain.

The network forming the context of animal health is shaped along the value-creation chain of products of animal origin. Accordingly, perception and discussion are heavily influenced by economic considerations. In this context qualitative attributes of animal health like prevalence of production diseases have no visible market value. For actors in livestock production it is questionable if effort in this field will pay off. Consequently, the lack of normative frames in the field of production diseases is leading to market distortion, favouring those who save on effort at the expense of animal health (Sundrum 2014).

It is important to recognize that the context described above determines the genesis of subjective knowledge among its individual members. Tàbara and Chabay (2013) refer to the network of agents and holders of knowledge in a specific context as 'knowledge system', providing the sense-making framework for learning and putting knowledge into meaningful practice. In the field of agriculture the concept of an ,Agricultural Knowledge and Innovation System (AKIS) ' describes the role of actors from several stakeholder groups for innovation in the food chain. It comprises actors from the supply chain (input supplier, farmer, food processor, retailer, consumer) as well as accompanying areas like commercial services, accountants, banks, press and NGOs and actors and organisations in the field of research, education and extension (EU SCAR 2012).

This description corresponds quite well with the stakeholders identified in the ESAs. Within the knowledge system (research-) questions are formulated and investigated. The context has a huge impact on which data are collected and considered. Furthermore, the context provides the background for the interpretation of data as well as the structure for communication and freedom to act. The 'knowledge system' in the field of animal health is characterised by heterogeneity of stakeholders mainly linked in the value-creation chain. This alone includes conflicting interests which are further extended by stakeholders from outside the value-creation chain, varying approaches and values 
concerning animal health. Following the concept of a 'knowledge system' it becomes obvious that within this heterogeneous network, data and information on animal health are inevitably regarded differently leading to varying demand for knowledge. Consequently, linear concepts of transferring information from scientific study to practice are doomed to fail due to the complexity of the biophysical systems and the socio- economic context.

\section{Schemas of context and their impact on cognition}

Beside the general description of the network forming the context in which the generation of data, preparation of information and creation of knowledge happens, the ESAs represent individual mental maps of the factual and social environment which hash an impact on animal health. These mental maps frame the individual perception and interpretation of data and information. Accordingly, the variation detected in the ESAs is an indicator for different understanding and different values.

Stakeholder groups identified in the ESAs have deviating reference to the topic of animal health, various starting points and different levels for action, partly resulting in conflicting interests. In the workshops conflicting interests manifested themselves in fault lines, discussed in WS 4 (see table 5). Contrary to expectation neither the proven method of "square of values" (Schulz von Thun 2010) (WS4) nor the "walking in the shoes of" - section in WS5/2 could support the development of workable solutions to bridge the gaps between different interests and foster the development of joint action plans, aimed in the long run at reduced prevalence of production diseases. Facing the heterogeneity in assessments and opinions on animal health and confronted with other perspectives, the participants seemed to seek coherence within their corresponding peer groups to underpin their positions.

The observation that participants slipped back into self-referential perspectives on individual and group levels in the situation of the common workshop (WS4) and day 2 of the NGOs Workshop (WS5/2) confirms the importance of coherence (e.g. with own world views or peer groups) revealed by Kahneman (2012) and Eidelman and Crandall (2009). van Bueren et al. (2014) identified competing and conflicting interests in the value chain of chicken meat as important barrier to improving sustainability. According to Eshuis and Stuiver (2005), conflicting areas among actors collaborating in a project is a risk factor to collaborative learning because it enhances self-referentiality, thereby limiting the learning to the individual frame of thought and hampering the reflection on the frame itself.

Jost and Banaji (1994) described the system justification motive as a strong driver in defending the status quo of a prevailing social or economic system. This motive appears to grow stronger with the perception of inevitability, growing assaults against the system and the perceived dependency of the individual. Stakeholders tend to justify their role and the system, even if they are disadvantaged by it; especially when the situation is perceived as unchangeable (Johnson and Fujita 2012). In the ESAs, participants revealed their impression of other stakeholders having considerable impact on animal health. The fact that most stakeholders are reliant on the value-creation chain supports the impression of path dependency. The discussion along the fault line of animal health and economy revealed accusations against the system of livestock production. The environment described by the participants in their ESAs seems therefore to foster system justification rather than progress towards the aim of reducing production diseases. Also in their study in the field of sustainability in chicken meat production van Bueren et al. (2014) concluded that self-justifying behaviour and actors stuck in path dependency are a key reason for not taking action. While the methodological approach of the ESAs supported a process of reflection during the workshops within the stakeholder groups, the common workshop with all participants revealed self-referentiality and system justification motives as inherent obstacles in the system of knowledge regarding animal health. 


\section{Individual perception of animal health}

The assessment of animal health situations was based on limited information, provided as pictures, data sets and a video. Therefore, the aim was not to evaluate right or wrong answers, but to capture the variation that occurs in the process of perception, interpretation and action. This refers to the internal character of knowledge, which is embodied in humans, depending on the context, and constructed by the knowledge holder (Probst et al. 2006). The pictures, the video and the data sets provided different amounts of information: while the pictures left the most room for individual perception and interpretation, the video clip provided much more information. In fact, the scores for the impairment of the general condition of the lame cow shown in the video, varied least. For the pathological findings presented by data sheets showing high levels of SCCs in a dairy herd and pathological findings on lung infections in fattening pigs, the perception of the visual presentation was expected to have lesser influence on the process of perception and interpretation, because the information was based on figures. Accordingly, the variation in the estimation of herd health situation based on the data sheets could be expected to be lower than in the cases presented by pictures. However, the variation in the interpretation of the SCCs and lung lesions was quite high, indicating large differences in the reference values of individuals concerning the evaluation of pathological findings, presumably leading to diverging sense of urgency.

Jansen et al. (2009) found variation in farmers' normative frame of reference to be a relevant explanation for variation in mastitis incidence. Self-referential assessments on udder health information were also reported by Garforth et al. (2013) and van Asseldonk et al. (2010) who found farmers acting self-referentially and not in relation to an external reference value by referring to farm level constraints and their specific beliefs in efficacy when arguing against the implementation of measures and considering actions with regard to SCCs.

The heterogeneous results on animals' health impairment and the judgement of herd health status indicate the subjective nature of perception, depending largely on individual frames or schemas (Leeuwis and Ban 2004; Probst et al. 2006; Liyanage et al. 2009). The importance of the farmer in the field of animal health came up in all ESAs, revealing his prime position in the process of efforts to reduce the prevalence of production diseases. Aiming for changes in behaviour, the individual perception of a situation is more important than the severity of the problem itself (Beratan 2007). Jansen and Lam (2012) referring to conventional, as well as Richert et al. (2013) referring to organic livestock production and small conventional farms have confirmed this conclusion in their studies in the field of animal health in dairy herds.

According to the heterogeneous assessments of the presented findings, the ranking of measures varied a lot within and between the workshop groups. In real on-farm situations this would lead to different recommendations (e.g. from a veterinarian and an advisor) which is seen as an important obstacle in the communication on animal health (Lam et al. 2011).

Contrary to the variation in assessments observed in this study, Wemelsfelder et al. (2012) found a high degree of inter- and intra-observer reliability in the qualitative assessment of body language of pigs between groups with different professional backgrounds (large animal veterinarians, pig farmers and pig protectionists). This could be explained by different qualitative target levels of observations. The qualitative behaviour assessment aimed at a subjective description of animal behaviour referring to what the animal itself experiences. Empathy for what animals' experience is rooted in the human mirror neuron system (White et al. 2014) and seems to provide comparable results independent of the observer's profession. In contrast, the health situation in a group of animals and the impact of a specific disease situation on animals' general condition refers to a construct, consisting of manifold information and therefore requires knowledge and subjective norms for its assessment. Nonetheless, in the field of 
communication on and improvement of animal health, the people directly involved are confronted by this complex situation in their day-to-day decision-making.

\section{Beyond self-reference}

Recognising a problem is the result of the perceived tension between a desired or expected situation and reality. Referring to the concept of schemas, forming the template for individual behaviour, awareness occurs when perception reveals an unexpected situation that does not fit the underlying schema. Accordingly, a process of learning, the search for a solution to a problem, will not start without demand arising from problem perception and requires the availability of information on the specific situation (Leeuwis and Ban 2004; Liyanage et al. 2009).

This is the starting point for concepts for advice, which is only addressed briefly in this article. Based on the insight that the transfer of knowledge does not follow the linear concept of transfer of technology (Röling 1988) new advisory concepts are centred on the perceived individual needs of the farmer and focussed on the farm context (Hoffmann and Albrecht 1989; Boland 1991; Darnhofer et al. 2012). While the still not overcome transfer of technology approach fails to work in the complex farm specific socio-economic context as well as the complex aetiology of production diseases, the farm focused advisory concepts are hampered by self-referential perception due to a lack of external reference values. Oppermann et al. (2008) found insufficient acceptance of individually designed animal health plans by organic farmers and identified attitudes of farmers as main cause for not taking up the strategic approach and support of a research project to improve animal health on their farms. The implementation of measures to improve animal health in organic dairy farms was higher in the more farm centric approach of 'stable schools' assessed in a pilot study in organic dairy farms in Germany. Farmers were highly motivated to follow the self-determined approach (March et al. 2014). The approach puts strong emphasis on the importance of internal knowledge, values and beliefs of the farmers but at the same time has a weak point in considering the needs of the dairy cows, reflected by health problems, independent from how important they are perceived by the farmer. Recommendations by Zapf et al. (2015) regarding the use of indicators for on-farm self-assessment of animal welfare include the systemically evaluation in a reference frame to overcome self-reference.

Assessing the decision processes in complex socio-ecological systems, Beratan (2007) identified norms and assumptions resulting from discourse in a network of social interactions as expression of cultural development and drivers for changes in a system. It can be assumed that reference values concerning the prevalence of production diseases could provide such normative orientation.

Recommending qualitative reference values instead of the dominating economic constraints puts faith in the aspect of resilience in a diverse network of stakeholders (Beratan 2007). This network has adjusted to the overwhelming challenges of the 'agricultural treadmill' in the past (Cochrane 1958; Röling 2009) and bears the potential to achieve more qualitative goals, given a normative frame that provides orientation and serves as safeguard against unfair competition. The latter occurs when products realize the same price irrespective of a certain quality which is of interest for common welfare (in this case the level of production diseases in a herd), putting those farms that invest in animal health at a disadvantage.

Binding normative values concerning an acceptable prevalence of production diseases would safeguard farms with a certain herd health status against unfair competition and reduce miscommunication by limiting the variety of underlying values and making them explicit (van Bueren et al. 2014). The focus on the prevalence of diseases takes into account the complex and emerging aetiology of health rather than defining minimum standards for input factors that does not necessarily lead to a good health status 
(Sundrum 2014). Furthermore, the reference to animal based values allows the animal to hold a role as stakeholder in this context.

\section{Conclusions}

Findings from the workshop process revealed a quite complex context for reflection on the animal health issue due to the plurality of stakeholders, huge variation in statements between and within stakeholder groups, and the manifold parameters to be considered within the farm system. The individual actors in the system of communication and operational structure do not have a general overview and operate from their self-referential perspective.

The theoretical construct "animal health" was understood quite differently by the stakeholders and proved to be not actionable in terms of measurability. By contrast, the frequency of production diseases is quantifiable and refers to the absence of disease as a necessary if not sufficient prerequisite for animal health. Levels for prevalence of production diseases should be established to overcome the lack of definition of animal health and serve as a strategic goal.

Differences in role expectations and vague perceptions of responsibilities were identified as obstacles in the system of communication structures and conditions, depicted in the ESAs. Self-referential judgements are an obstacle inherent in the system when striving for increased implementation of knowledge to reduce production diseases. This conclusion is in line with the findings of van Bueren et al. (2014), who referred to 'organised irresponsibility' and institutional inertia in his analysis of the Dutch chicken meat sector and Jonge and Trijp (2013), who identified the status of 'system-lock in' in the European meat supply chain. We conclude that the current communication structure, identified in the network of stakeholders, is not suitable for enabling a targeted transfer of information and the generation of knowledge aimed at a reduced prevalence of production diseases.

\section{References}

Arce A, Long N (1987) The dynamics of knowledge interfaces between Mexican agricultural bureaucrats and peasants: a case study from Jalisco. Boletín de Estudios Latinoamericanos y del Caribe:5-30. http://www.jstor.org/stable/25675346.

Beck U (1992) Risk society towards a new modernity. Sage Publ, Los Angeles [u.a.].

Beratan KK (2007) A cognition-based view of decision processes in complex social-ecological systems. Ecology and Society 12:27.

Boland H (1991) Interaktionsstrukturen im Einzelberatungsgespräch der landwirtschaftlichen Beratung. Zugl.: Gießen, Univ., Habil.Schr. Wiss.-Verl. Vauk, Kiel.

Brown J (2005) The world café: Shaping our futures through conversations that matter. Berrett-Koehler Store.

Carlile PR, Rebentisch ES (2003) Into the Black Box: The Knowledge Transformation Cycle. Management Science 49:1180-1195.

Cicconi-Hogan KM, Gamroth M, Richert R, Ruegg PL, Stiglbauer KE, Schukken YH (2013) Associations of risk factors with somatic cell count in bulk tank milk on organic and conventional dairy farms in the United States. J Dairy Sci 96:3689-3702.

Clarkson MBE (1995) A Stakeholder Framework for Analyzing and Evaluating Corporate Social Performance. The Academy of Management Review 20:92-117. http://www.jstor.org/stable/258888.

Cochrane WW (1958) Farm prices : myth and reality. Univ. of Minnesota, Minneapolis.

Darnhofer I, Gibbon D, Dedieu B (2012) Farming Systems Research into the $21^{\text {st }}$ Century: The New Dynamic. Springer Netherlands, Dordrecht.

Dijkhuizen AA, Huirne R, Jalvingh AW (1995) Economic analysis of animal diseases and their control. Veterinary Epidemiology and Economics. Preventive Veterinary Medicine 25:135-149.

Eidelman S, Crandall CS (2009) A psychological advantage for the status quo. In: Jost JT (ed) Social and Psychological Bases of Ideology and System Justification. Oxford Univ. Press, Oxford [u.a.], pp 85-106.

Eshuis J, Stuiver M (2005) Learning in context through conflict and alignment: Farmers and scientists in search of sustainable agriculture. Agric Hum Values 22:137-148.

EU SCAR (ed) (2012) Agricultural knowledge and innovation systems in transition. A reflection paper. EUR-OP, Brussels.

Freeman RE (1984) Strategic management a stakeholder approach. Pitman, Boston.

Garforth CJ, Bailey AP, Tranter RB (2013) Farmers' attitudes to disease risk management in England: A comparative analysis of sheep and pig farmers. Preventive Veterinary Medicine 110:456-466.

http://www.sciencedirect.com/science/article/pii/S0167587713000676. 
Gröhn YT, Eicker SW, Ducrocq V, Hertl JA (1998) Effect of diseases on the culling of Holstein dairy cows in New York State. J Dairy Sci 81:966-978.

Harper GC, Makatouni A (2002) Consumer perception of organic food production and farm animal welfare. British Food Journal 104:287-299.

Harris SG (1994) Organizational Culture and Individual Sensemaking: A Schema-Based Perspective. Organization Science 5:309-321. http://dx.doi.org/10.1287/orsc.5.3.309.

Hermansen JE (2003) Organic livestock production systems and appropriate development in relation to public expectations. Organic Livestock Production 80:3-15. http://www.sciencedirect.com/science/article/pii/S0301622602003135.

Hoffmann V, Albrecht H (eds) (1989) 1. Basic concepts and methods. GTZ [u.a.], Eschborn.

Hudson JT, Slater MR, Taylor L, Scott HM, Kerwin SC (2004) Assessing repeatability and validity of a visual analogue scale questionnaire for use in assessing pain and lameness in dogs. American Journal of Veterinary Research 65:1634-1643.

International Federation of Organic Agriculture Movements (IFOAM) (2014) The IFOAM Norms for Organic Production and Processing. Version July 2014. http://www.ifoam.bio/sites/default/files/ifoam_norms_version_july_2014.pdf. Accessed 7 January 2016.

Jansen J, Lam TJ (2012) The Role of Communication in Improving Udder Health. Veterinary Clinics of North America: Food Animal Practice 28:363-379. 22664213.

Jansen J, van den Borne, B.H.P., Renes RJ, van Schaik G, Lam T, Leeuwis C (2009) Explaining mastitis incidence in Dutch dairy farming: The influence of farmers' attitudes and behaviour. Preventive Veterinary Medicine 92:210-223.

Johnson IR, Fujita K (2012) Change We Can Believe In: Using Perceptions of Changeability to Promote System-Change Motives Over System-Justification Motives in Information Search. Psychological Science 23:133-140.

Jonge J de, Trijp HCM van (2013) Meeting Heterogeneity in Consumer Demand for Animal Welfare: A Reflection on Existing Knowledge and Implications for the Meat Sector. J Agric Environ Ethics 26:629-661.

Jost JT, Banaji MR (1994) The role of stereotyping in system-justification and the production of false consciousness. British Journal of Social Psychology 33:1-27. http://dx.doi.org/10.1111/j.2044-8309.1994.tb01008.x.

Kahneman D (2012) Thinking, Fast and Slow. Penguin Books, London.

Kjærnes U (2012) Ethics and Action: A Relational Perspective on Consumer Choice in the European Politics of Food. J Agric Environ Ethics 25:145-162.

Lam T, Jansen J, van den Borne, BHP, Renes RJ, Hogeveen H (2011) What veterinarians need to know about communication to optimise their role as advisors on udder health in dairy herds. New Zealand Veterinary Journal 59:8-15.

Leeuwis C, Ban A van den (2004) Communication for rural innovation. Rethinking agricultural extension, $3^{\text {rd }}$ edn. Blackwell Science; Iowa State Press, for CTA, Oxford, Ames, Iowa.

Legendre P (2010) Coefficient of concordance. In: Salkind NJ (ed) Encyclopedia of research design. SAGE reference, Los Angeles [etc.], pp 164-169.

Liyanage C, Elhag T, Ballal T, Li Q (2009) Knowledge communication and translation - a knowledge transfer model. Journal of Knowledge Management 13:118-131. info:Journal Acronym:jkm.

Magnusson MK, Arvola A, Hursti U-KK, Åberg L, Sjödén P-O (2003) Choice of organic foods is related to perceived consequences for human health and to environmentally friendly behaviour. Appetite 40:109-117. http://www.sciencedirect.com/science/article/pii/S0195666303000023.

March S, Brinkmann J, Winckler C (2014) Improvement of animal health in organic dairy farms through 'stable schools': selected results of a pilot study in Germany. Organic Agriculture 4:319-323. http://dx.doi.org/10.1007/s13165-014-0071-5.

Mayring P (2010) Qualitative Inhaltsanalyse. Grundlagen und Techniken, 11th edn. Beltz, Weinheim.

McInerney JP, Howe KS, Schepers JA (1992) A framework for the economic analysis of disease in farm livestock. Preventive Veterinary Medicine 13:137-154.

Nerdinger FW (2012) Grundlagen des Verhaltens in Organisationen, 3rd edn. Kohlhammer, Stuttgart.

Nir O (2003) What are Production Diseases, and How do we Manage them? Acta Vet Scand 44:P1.

Oppermann R, Rahmann G, Göritz M, Demuth G, Schumacher U (2008) Soziologische Untersuchungen zur Implementation von Tiergesundheitsplänen im Ökologischen Landbau. Landbauforschung - vTI Agriculture and Forestry Research 3:179-190. http://literatur.thuenen.de/digbib_extern/bitv/dk040430.pdf.

Probst GJ, Raub S, Romhardt K (2006) Wissen managen. Wie Unternehmen ihre wertvollste Ressource optimal nutzen, 5th edn. Betriebswirtschaftlicher Verlag Dr. Th. Gabler / GWV Fachverlage GmbH, Wiesbaden, Wiesbaden.

Richert RM, Cicconi KM, Gamroth MJ, Schukken YH, Stiglbauer KE, Ruegg PL (2013) Risk factors for clinical mastitis, ketosis, and pneumonia in dairy cattle on organic and small conventional farms in the United States. J Dairy Sci 96:4269-4285.

Ringberg T, Reihlen M (2008) Towards a Socio-Cognitive Approach to Knowledge Transfer. Journal of Management Studies 45:912935 .

Röling N (1988) Extension science. Information systems in agricultural development. Cambridge Univ. Press, Cambridge.

Röling N (2009) Pathways for impact: scientists' different perspectives on agricultural innovation. International Journal of Agricultural Sustainability 7:83-94.

Rossi J, Garner SA (2014) Industrial Farm Animal Production: A Comprehensive Moral Critique. J Agric Environ Ethics 27:479-522.

Roux DJ, Rogers KH, Biggs H, Ashton PJ, Sergeant A (2006) Bridging the science-management divide: Moving from unidirectional knowledge transfer to knowledge interfacing and sharing. Ecology and Society 11. http://www.ecologyandsociety.org/vol11/iss1/art4/.

Schlippe A von, Schweitzer J (2012) Lehrbuch der systemischen Therapie und Beratung I. Das Grundlagenwissen. Vandenhoeck \& Ruprecht, Göttingen. 
Schulz von Thun F (2010) Miteinander reden: Störungen und Klärungen. Allgemeine Psychologie der Kommunikation. Allgemeine Psychologie der Kommunikation, 46th edn. Rowohlt Taschenbuch-Verlag, Reinbek bei Hamburg.

Sundrum A (2012) Health and Welfare of Organic Livestock and Its Challenges. In: Ricke SC, van Loo EJ, Johnson MG, O'Bryan CA (eds) Organic Meat Production and Processing // Organic meat production and processing. Wiley-Blackwell; John Wiley and Sons, Oxford, UK, pp 87-112.

Sundrum A (2014) Organic Livestock Production. In: Van Alfen, Neal K. (ed) Encyclopedia of agriculture and food systems. Elsevier, San Diego, pp 287-303.

Sundrum A, Goebel A, Bochicchio D, Bonde M, Bourgoin A, Dietze K, Dippel S, Hegelund L, Leeb T, Lindgren K, Prunier A, Wiberg S (2010) Health status in organic pig herds in Europe. In: Int. Pig Veterinary Society (IPVS) (ed) Proceed. $21^{\text {st }}$ Int. Pig Veterinary Society (IPVS) Congress.

Tàbara DJ, Chabay I (2013) Coupling Human Information and Knowledge Systems with social-ecological systems change: Reframing research, education, and policy for sustainability. Special Issue: Responding to the Challenges of our Unstable Earth (RESCUE) 28:71-81. http://www.sciencedirect.com/science/article/pii/S1462901112002080.

Vaarst M, Alrøe HF (2012) Concepts of Animal Health and Welfare in Organic Livestock Systems. J Agric Environ Ethics 25:333-347.

Vaarst M, Padel S, Younie D, Hovi M, Sundrum A (2008) Animal health challenges and veterinary aspects of organic livestock farming identified through a 3 year EU network project. Open Veterinary Science Journal 2:111-116. http://centaur.reading.ac.uk/17925/1/111TOVSJ.pdf.

van Asseldonk MA, Renes RJ, Lam, T. J. G. M., Hogeveen H (2010) Awareness and perceived value of economic information in controlling somatic cell count. Veterinary Record 166:263-267.

van Bueren EM, Lammerts van Bueren ET, van der Zijpp AJ (2014) Understanding wicked problems and organized irresponsibility: challenges for governing the sustainable intensification of chicken meat production. SI: Sustainability governance and transformation 8:1-14. http://www.sciencedirect.com/science/article/pii/S1877343514000335.

Vanhonacker F, van Poucke E, Tuyttens F, Verbeke W (2010) Citizens' Views on Farm Animal Welfare and Related Information Provision: Exploratory Insights from Flanders, Belgium. J Agric Environ Ethics 23:551-569.

Ventura BA, von Keyserlingk, M. A. G., Weary DM (2014) Animal Welfare Concerns and Values of Stakeholders Within the Dairy Industry. J Agric Environ Ethics.

Vetter H (2012) Projektumfeldanalyse. In: Rohm A (ed) Change-Tools: Erfahrene Prozessberater präsentieren wirksame WorkshopInterventionen, $5^{\text {th }}$ edn. ManagerSeminare-Verl.-GmbH, Bonn, p 100.

Wemelsfelder F, Hunter AE, Paul ES, Lawrence AB (2012) Assessing pig body language: agreement and consistency between pig farmers, veterinarians, and animal activists. Journal of animal science 90:3652-3665.

White NC, Reid C, Welsh TN (2014) Responses of the human motor system to observing actions across species: A transcranial magnetic stimulation study. Brain and Cognition 92:11-18. http://www.sciencedirect.com/science/article/pii/S0278262614001535.

Wilkesmann M, Wilkesmann U (2011) Knowledge transfer as interaction between experts and novices supported by technologynull. VINE 41:96-112.

Zander K, Hamm U (2010) Consumer preferences for additional ethical attributes of organic food. Food Quality and Preference 21:495-503. http://www.sciencedirect.com/science/article/pii/S0950329310000078.

Zapf R, Schultheiß U, Achilles W, Schrader L, Knierim U, Herrmann H-J, Brinkmann J, Winckler C (2015) Indikatoren für die betriebliche Eigenkontrolle auf Tiergerechtheit - Beispiel Milchkühe. LANDTECHNIK - Agricultural Engineering 70:221-230.

Zins C (2007) Conceptual approaches for defining data, information, and knowledge. J. Am. Soc. Inf. Sci. 58:479-493. http://dx.doi.org/10.1002/asi.20508. 